\title{
Application of British National Corpus to the Teaching and Learning of Synonyms in English Language in Some Selected Higher Institutions in Nigeria
}

\author{
Josephine Ohiemi \\ Department of English and Literary Studies Federal University Lokoja \\ Email:johems@yahoo.com \\ Olaoluwa Duro-Bello \\ Department of English and Literary Studies Federal University Lokoja \\ Email: olazee4eva@yahoo.com \\ James Udaa \\ Department of English and Literary Studies Federal University Lokoja \\ Email:jimudaa@gmail.com
}

Doi:10.5901/ajis.2015.v4n2p357

\section{Abstract}

This paper highlights the potential benefits of software application to teaching and learning of synonymy in higher education. Synonymy is often misconstrued as a ubiquitous area of knowledge among language teachers and learners. However, further scrutiny reveals limitless possibilities which teachers appear to have taken for granted, especially in their use of technology in the teaching process. The research methodology comprises questionnaires administered to English language teachers in selected schools. Linguistic data was collected from the British National Corpus (BNC) using search words which are near synonyms (as taught in schools) to investigate the relatedness of these words. The outcome indicates significant differences in the results of synonyms generated on BNC compared with those taught by teachers in the classrooms. The study showed that using ICT in language teaching and learning has potential and valuable evidence to show that the adoption of software to concepts in English language teaching and learning is an opportunity to acquire new technology and enhance the pleasure of learning. The increased learning possibilities which the adoption of ICT in this way will engender have transformative potentials in teaching and learning English in Higher Education.

Keywords: ICT, British National Corpus, Synonymy and Higher Education.

\section{Introduction}

It has been observed that English language use in natural communicative situations is similar to the type of English which teachers and learners are confronted with in a foreign language teaching context. This increases the degree of authenticity and naturalness of language. The traditional teaching materials for teaching and learning of synonymy in schools in Nigeria are the dictionary and thesaurus. The present dispensation of increasing possibilities of language use makes these instruments inadequate. Corpus evidence of language must be taken seriously because the data indicates a reservoir of untapped possibilities which are beyond the use in context and description of linguistic phenomena in the current teaching materials.

The various ways in which corpus application to 'common' concepts of language teaching and learning such as synonyms brings out such peculiarities is the focus of this study. The potentials and related challenges of the application of British National Corpus (BNC) to teaching synonymy in English language are discussed and evaluated. The BNC shows that particular words have particular grammatical and semantic characteristics depending on the frequencies with which they are experienced.

Using corpus-based evidence in the nature of synonyms presented in this study, the teaching and learning of synonymy might be expected to have more explicit and prominent place in language teaching curriculum. It is envisaged that this form of application of technology could be helpful to English language pedagogy. 


\section{Research Questions}

The study seeks to answer the following questions:

1) How is synonymy taught in institutions of Higher Education in Nigeria?

2) What are the features of English synonyms generated without the use of a corpus?

3) Is there any significant difference between such synonyms and those generated using the British National Corpus?

4) If they differ, how can corpus evidence help to improve language teaching and learning of synonyms?

\section{Literature Review}

\subsection{Synonym}

Word semantics is a very important aspect of words and their relation. Often, this border on semantic preference and how people account for word meaning (Cruse, 1986). Synonym is a form of lexical relation whereby, two or more forms with closely related meaning, often, but not always are intersubstitutable in sentences (that is not same denotation). Murphy, (2010) emphasizes the idea of 'nearness of meaning' or 'relative sameness' but not 'total sameness' or 'perfect sameness'. The users recognize several occasions and formalities whereby one word is more appropriate in a sentence but its synonym would not be useful, for example 'answer' and 'reply'.

When reference is made to fluidity in meaning relation, the focus is about to which extent these words relate and what is remaining that makes them exactly the same. This implies that, in the case of 'near synonymy' the words' sense overlaps and can be substituted in some contexts but not in every context. This difference can manifest when words are being polysemous in different ways such as in dialects and registers. This could also result from borrowed words that are present in English language. These imply that in instances of 'near synonyms' there are distributional differences. Choice of word is very significant because of the shift in meaning that is possible with each choice. The logic in meaning relation in a context accounts for small differences and appropriate choice of words in discourse.

\subsection{British National Corpus}

The British National Corpus (BNC) is a web-derived corpus of texts. Language technology applications have huge amount of texts that have become available electronically as a source of empirical evidence, data-intensive methods and shared resources ( for example annotated corpora) that allow these evidences to be found and used. There are several types of electronic corpora. The list includes Brown Corpus (LOB), Corpus of Contemporary American English (COCA), COBUILD amongst others. There are smaller corpora of texts but BNC is the largest. BNC is a one hundred million (ninety-nine million written and ten million spoken) representative of language variety/genre. It was compiled between 1980s-1993 and has multiple interfaces that can generate diverse data concerning word frequencies, concordance, text types, collocations and contextual behaviour of words and synonymy. BNC follows the Birmingham corpus linguistic tradition of bottom-up which leads to decrease in learning problems (Davies, 2011).

\subsection{National Policy on Education and Educational Technology in Nigeria}

The history of educational technology is traceable to the colonial era when the managers of voluntary agency schools emphasized the use of teaching aids. This evolved into the use of hardware approach and other low cost materials before 1933. However, international organizations such as United Nations Educational Scientific and Cultural Organization (UNESCO), Centre for Education Development Overseas (CEDO) and the Ford Foundation amongst several others offered contributions, support and expert advice that constituted the foundation of the use of educational technology in Nigeria (Adewoyin, 1991). This led to Ministry of Education establishing audio-visual units and the school broadcasting units in the three regions in Nigeria. These centres led to the emergence of the National Educational Technology Centre, Kaduna in 1977.

The National Policy on Education (1981) devotes section 10, pages $42-43$ to "Educational Services". This includes objectives of how to utilize educational technology to develop, assess and improve educational programmes; enhance and improve competence of teachers; make learning more meaningful for children and reduce educational costs. Other aims include promoting in-service education and to develop and promote an effective use of innovative materials in 
schools. Strategies of implementation put in place include to establish Teachers Resource Centres in all states; to establish Curriculum Development Centres; to provide fund to the NERDC and the universities by both Federal and State governments and to establish language centres, educational resource centres, science and mathematics centres, workshops, libraries and guidance and counselling centres. These are very laudable ambitions in reference to what is referred to as Educational Services, Media Resource Centres, Audio-visual Centre, teaching aids or any of the evolutionary names in the teaching/learning processes which reflect the different stages of growth.

Thus, computer technology and technology supported learning is recognized in the National Policy on Education. At the conceptual level, the goals are to involve technology in formal and non-formal education because technology has numerous potentials for both teachers and students.

\subsection{Technology and Foreign Language Pedagogy}

Xiaoyin.H; Dedegikas, C and Walls, J (2011) emphasize that Internet-based technologies are extremely useful resources for teachers and learners of foreign language because various innovations have revolutionized approaches to teaching and learning foreign language. Technology-Based Language Learning (TBLL) includes Computer-Assisted Language Learning (CALL);; Mobile-Assisted Language Learning (MALL); Internet-Based Language Learning (IBLL); Online Language Learning (OLL); Google-Assisted Language Learning (GALL) and Technology Enhance Language Learning (TELL) amongst others. Different forms and to different degrees, media has allowed students/learners to use specific language instruction software.

In Nigeria, since 1960s to date, this usage can be seen as ranging from listening to language files to watching YouTube videos. Xiaoyin.H; Dedegikas, C and Walls, J (2011) demonstrate how multimedia technology combined with appropriate instructional designs create a good language environment that is highly motivational and leads to effective language learning. Internet-based software has a pedagogical tool in acquiring foreign language competency, autonomous learning and gaining more intercultural literacy (Warschaue, 1996). Internet-based software has transformed the way foreign languages are taught across language borders. The suggested advantages include possibilities of independent study and access to more structured learning. Though there are various opinions on the relevance of technology to teaching and learning, Adina,L; Ferenz, $O$ and Reves, T (2000) state that literature has it that Internetbased technologies are useful resources for teachers and learners of foreign language.

\subsection{Implications of BNC for the Teaching and Learning of Synonymy}

Murphy (2013) states that the traditional teaching and learning of synonymy is carried out primarily with the use of dictionary and Thesaurus. The dictionary entry style accounts predict relation of words on the basis of words' common semantic properties (without non-denotation properties such as sound and social register) in the mental lexicon. These forms of synonymous relations include linguistic knowledge people reason about. This is often based on the breakdown of lexemes into smaller parts. This implies that information needed for predicting synonym relation among words is available in relation to componential definition Dictionaries give good information and provide a useful starting point for investigating difference in the meaning between words. The general uses of synonyms match common dictionary definitions. However, the dictionary often conflates senses that may be useful to distinguish synonyms. Thesaurus account explicitly represents those relations in the lexicon. Corpus considers relations that involve other properties that words may have. This extends dictionary approach to consider non-denotation issues mentioned in the words' lexical entries.

Imogie (1985) quotes Armsey and Dahl (1973) as saying that the functions of educational technology include improving instruction (qualitative), to educate more people (quantitative) and to learn about learning (research). Other functions include reforming the curriculum (substance), to improve the process (method) and to articulate the system (structure). By extension, these functions apply to BNC.

Though there are differing opinions about the benefits of Computer Assisted Language Learning (CALL) to teaching and learning, the comparison of computer-assisted results of the synonyms of good and great and the traditional classroom teaching materials results make it possible to insinuate that they are potentials of the former in several ways.

A major advantage of BNC is the size of available data (100 million words) in both spoken and written form (British National Corpus, 2000). There is increasing evidence of relationship between language theories and Computer-Assisted Language Learning. This makes teaching and learning easier to target measurable objectives based on researched learning theories and makes instruction more scientific and systematic. Explicit instructions make it easier for technology 
to address routine jobs of information transmission and allow learners to learn with speed and accuracy while teachers do more creative work such as marking and recording.

Norris, J.M and Ortega, L. (2006) state that English Language textbooks differ from one another and textbooks also vary in use from real language because books drift away from typical used language patterns. Written materials are supposed to follow pedagogical principles therefore English textbooks are supposed to be more comparable. Corpus has the potential of providing a data base with unified forms of language. The unified version is very important because it gives learners a platform which checkmates the negative effects of diverse previous educational background. BNC for example, gives equal access to education on synonyms. This makes education become more productive as learners at any location can gain access to the best libraries in the world. The effectiveness of pedagogy supported by computer technology (BNC) promotes language development (Norris and Ortega, 2006: 33).

Davies, J. R (2011) emphasizes that globalisation and ICT meet the increasing need for blended learning models in language teaching and learning. This creates a positive impact and changes the teaching and learning process in our education space because mobile technologies result in portable classrooms. Therefore, hybridization of teaching and learning these language concepts (synonyms) has positive impact in instructional design because how to plan for long term improvement efforts in a pluralistic world would be a focus.

Software application helps to individualize instruction to rhyme with individual learners' need. Individual learners can go at his/her own speed and time because it is self-instructional and promotes self instruction. Using BNC is a state of the arts experience that gives learners insight on how to perform linguistic research and develop ability for enquiry and discovery. The software promotes retention (Adina, L. etal: 2000) because all the sensory organs are use simultaneously to see, touch and so on by the learner.

\section{Methodology}

The research methodology includes the analysis of data generated from BNC and the use of questionnaire. The primary data is collected from the BNC using a pair of near synonyms 'good' and 'great' as search words to determine whether there is any significant difference from the results generated on BNC. This pair has the highest frequency (90\%) in response to the questionnaire question (No.13). BNC is chosen for this research because of its size and because the interface incorporates grammatical tagging of each word. The latter facilitates automatic retrieval and analysis. The result of this pair is subjected to analysis and interpretation.

The secondary data is a questionnaire administered to English Language lecturers in six Federal Universities in Nigeria. The list of approved Federal Universities in Nigeria on the National Universities Commission (NUC)'s website shows forty (40) institutions. By stratified sampling, six were picked using the six geo-political zones as a guide. Random sampling was carried out to decide respondents. Other inclusion and exclusion criteria used include a vibrant school website and detailed academic staff profile, institutions offering English Language at a minimum of first degree, year of establishment and relevant research interests and publications of the staff. The questionnaires were sent and retrieved via email. Few phone calls were made to lecturers whose phone numbers were provided on the school websites. Each of these has different values added to the research. In all, fourteen (14) questionnaires were sent out and ten (10) were retrieved. The list of the selected institutions and other details resulting from the stratified sampling is attached as Appendix (i).

\subsection{Procedure}

Ninety percent (90\%) of respondents indicated that good and great are synonymous. These words were used as search words on BNC. In an attempt to investigate the collocates of good and great each lexeme was entered into the search box of the BNC. Using the 'collocates' function, a plot range was set at zero (0) words to the left of the search word and one (1) word to the right. This procedure was carried out for both good and great.

To generate results for distribution of good and great, each is written respectively in the 'search field' then 'chart option' is selected. When command is given using the 'search' button the result displays showing all the text types, frequencies and their percentages per million.

\subsection{Findings}

At first glance of the collocation list, it is clear that good collocates with nouns. The table below shows the 10 most 
frequent collocates of the word good.

Table 3.1

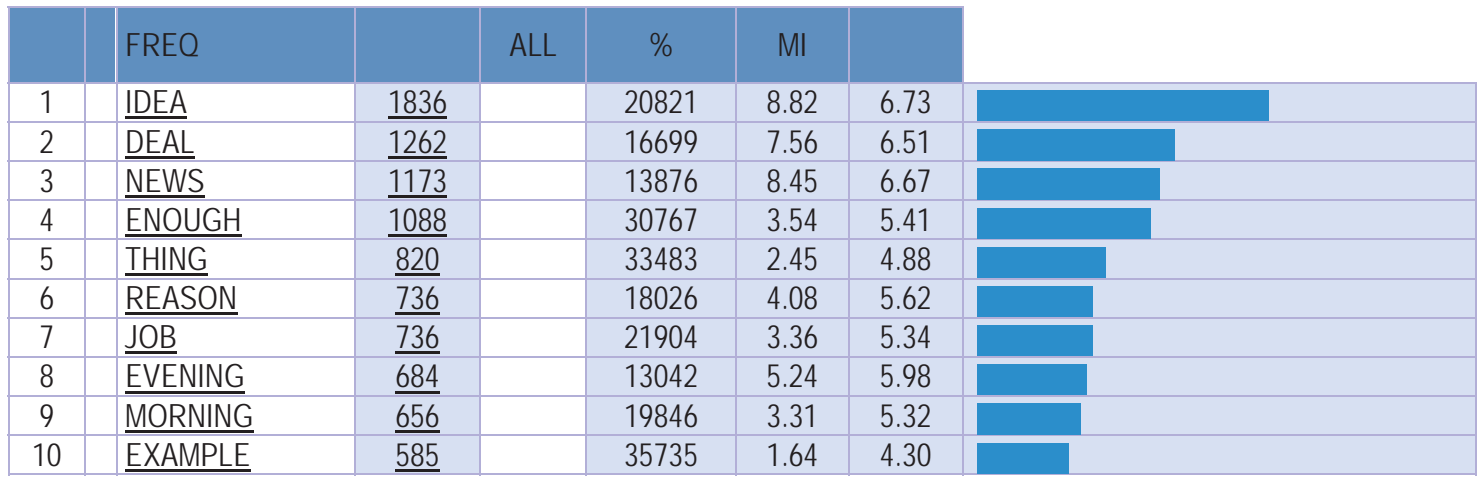

The results in Table 3.1 indicate that the most frequent words that collocate with good are 'idea', 'deal', 'news', 'enough', 'thing', 'reason', 'job', 'evening', 'morning' and 'example'. The results were displayed using 100 collocates list but only the first 10 words were used as sample. The table therefore shows the collocates, alongside their frequencies, percentages and word per million.

In Table 3.2 great was also found to collocate with nouns such as 'Britain', 'Western', 'Yarmouth', 'Northern' and 'Ayton'. These nouns are different from those that collocate with good because these are proper nouns. Below is a table showing the 10 words that frequently collocate with the adjective great with their frequencies, percentages, and word per million. In Table 3.2 Britain, a proper noun stands out as the second highest in terms of frequency.

Table 3.2

\begin{tabular}{|c|c|c|c|c|c|c|}
\hline 1 & DEAL & $\underline{3986}$ & 16699 & 23.87 & 8.96 & \\
\hline 2 & BRITAIN & $\underline{1656}$ & 24601 & 6.73 & 7.13 & \\
\hline 3 & $\overline{\text { MANY }}$ & 472 & 87792 & 0.54 & 3.49 & \\
\hline 4 & $\overline{\mathrm{BIG}}$ & $\overline{397}$ & 24382 & 1.63 & 5.09 & \\
\hline 5 & MAJORITY & $\underline{386}$ & 9634 & 4.01 & 6.39 & \\
\hline 6 & SUCCESS & $\underline{367}$ & 13070 & 2.81 & 5.87 & \\
\hline 7 & $\overline{\text { INTEREST }}$ & $\underline{320}$ & 26773 & 1.20 & 4.64 & \\
\hline 8 & IMPORTANCE & $\overline{317}$ & 9532 & 3.33 & 6.12 & \\
\hline 9 & CARE & $\underline{289}$ & 24178 & 1.20 & 4.64 & \\
\hline 10 & DIFFICULTY & $\underline{260}$ & 6185 & 4.20 & 6.46 & $\overline{7}$ \\
\hline
\end{tabular}

From the generated result (Table 3.3) of a chart display of distribution across different text types for the period of 1980s1993 from BNC shows that, the two adjectives good and great occur in all the text types; spoken, fiction, magazine, newspaper, non-academic, academic, and miscellaneous. According to the distribution, good has a total number of 79876 frequency and 829.77 per million across the text types. The number of frequency used in the spoken genre is about 16681 and 1,674.18 per million, fiction has a frequency of 16418 and 1,031.97 per million, magazine has a frequency of 7807 and a total of 1,075.05 per million, newspaper has a frequency of 8104 and a total 774.29 per million, non-academic has a total frequency of 7701 and a total of 466.86 per million, academic has the least frequency of 6221 and also the least of 405.76 per million, and finally, miscellaneous (misc) has a total frequency of 16944 and 813.24 per million. Therefore, this distribution shows that good occurred mostly in spoken medium with the highest frequency of 16681 and 1,674.18 per million. 
Table 3.3

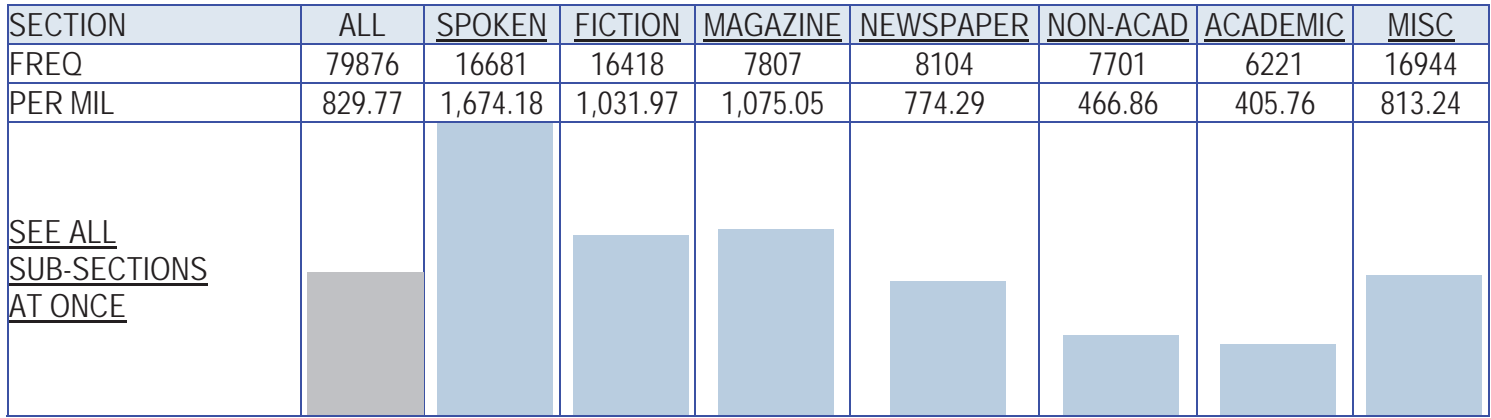

\subsection{Great}

The distribution for great (Table 3.4) indicates that a total of 46108 frequency and 478.98 per million occurred across all the text types. The total number of frequency used in the spoken medium is about 3875 and 388.91 percent per million, while fiction has a total number of 7565 frequency with 475.51 percent per million, magazine has 4188 frequency with 576.70 percent per million, newspaper has a total of 4876 frequency and 465.87 percent per million, non-academic has a total frequency of 8064 and 488.87 percent per million, while academic has a frequency of 5592 and 364.74 percent per million, and finally miscellaneous. has a frequency of 11948 and 573.45 percent per million. This distribution also shows that great occurred mostly in non-academic discourse with a highest frequency of 8064 and also 488.87 percent per million.

Table 3.4

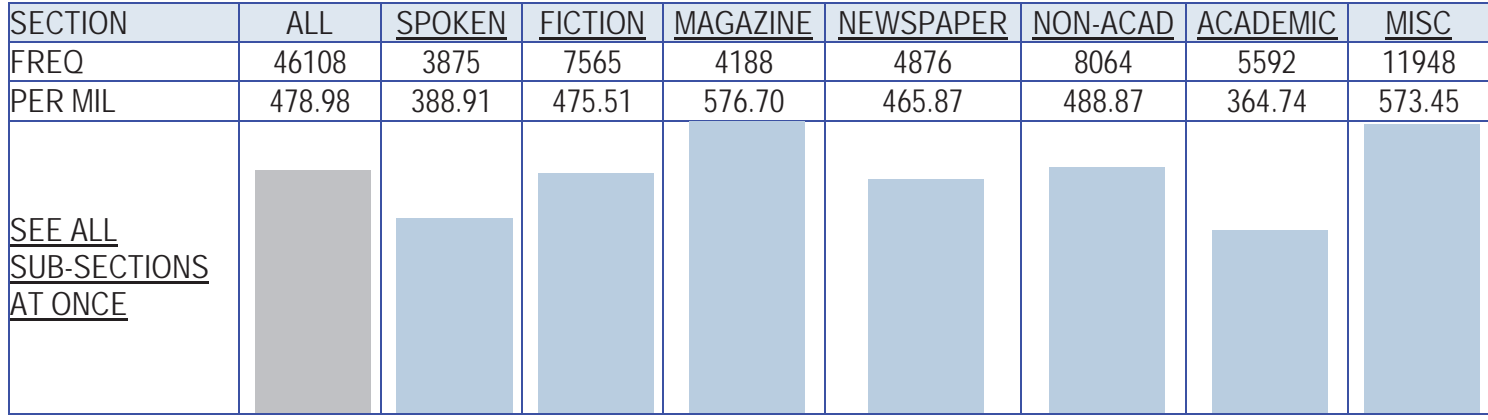

Both the adjectives occurred in all the above mentioned text types, but good occurred mostly in spoken texts with total of 16681 frequencies and occurred less in academic discourse with a total of 6221 frequency. Great occurred mostly in nonacademics texts with a total frequency of 8064 and occurred less in spoken texts with total frequency of 3875 and 388.91 percent per million. This analysis is generated from BYU-BNC. The generated result was obtained when the adjectives were written into the 'search field' then the 'chart' option was selected. When command was given using the search button the result displayed showed all the text types, frequencies and their percentages per million. Comparison of the result of both is carried out and interpretation to the data is done manually before conclusion is drawn concerning the relatedness of the supposedly synonyms good and great.

\subsection{Interpretation}

Based on the difference in the words that both words collocate with, the outcome refutes the claim that good and great are synonyms. The study proved that though both adjectives pre-modify nouns, the kinds of nouns they pre-modify are different hence they cannot be synonymous. To further support this position, the genres where great occurs most frequently compared to those that good occurs most frequently vary. This suggests that the use of either good or great is context dependent because there are instances where the use of one is more appropriate than the use of the other. 


\subsection{The Potential Benefits of BNC Application to the Teaching and Learning of Synonymy}

1) The most important outcome of corpus-based insights into what language learning entails may be in consciousness-raising for teachers. At the professional level, language educators have been challenged by corpus linguistics to work out how to maximize the exposure learners need to acquire probabilistic implicit knowledge. Data of the magnitude in BNC reveals something of the cognitive processes that lie behind language learning and use and that which enable individuals to become fluent language user.

2) BNC provides the teacher with the opportunity of arousing, generate and sustaining the interest of learners and promote positive attitude to learning; vary his mode of instruction using different devices.

3) A major implication of BNC application to synonymy for national development is that Nigeria students come from very wide educational background of which the teachers have no control over the variables. But the teachers have got control over how to educate the learners so that the learners are more able to take control of their lives as learners.

4) The available data on BNC is very large (100 million words), in unified forms and it contains explicit instructions with learners' friendly interface. This gives learners equal access and makes learners work with their personal peculiarities.

5) Software application (BNC) is self-instructional and promotes self instruction.

6) New technologies like the BNC and its application allows learners to become increasingly autonomous in learning foreign language, foreign language competency and gain intercultural literacy.

7) BNC application to synonyms has the advantage of improving overall English Language competence; enhance oral communication and other language skills.

8) Using BNC is a state of the arts experience that gives learners insight on how to perform linguistic research and develop ability for enquiry and discovery. The software promotes retention because all the sensory organs are use simultaneously to see, touch and so on by the learner.

9) The effectiveness of pedagogy supported by computer technology (BNC) promotes language development.

10) Corpus application (BNC) enables language learners develop reflective learning strategies that aid pedagogical framework.

11) Internet-based technologies in general are very useful resources for teachers and learners of foreign language. The primary and secondary skills activated by software applications have numerous positive implications for national growth and development.

\subsection{Challenges of Effective Practice of Educational Technology in Nigeria}

1) Ten (10) questionnaires were retrieved out of the fourteen (14) that were emailed to respondents. One respondent (out of the ten, which represents 10\%) has been exposed to the application of BNC to synonyms. This suggests likely ignorance of the availability of such concepts and the likely advantages of using such in teaching and learning. The response also implies a lack of professional/academically trained personnel in BNC in practice in Nigerian institutions turning up countless man power for learners.

2) Bureaucratic bottlenecks, rigid organizational structures against innovation and poor reward system constrain innovative techniques of educational technology.

3) The poor response in the questionnaire could also be an indication that Nigerian institutions are ill-equipped for educational technology. This is likely to be outcome of poor funding and poor financial allocation for the educational institutions, Educational Technology and other related institutions [power supply, teachers' training (lack of professionalization of educational technology), poor teachers' remunerations, production of educational media in Nigeria and subsidy for maintenance and spare parts outlets] in Nigeria (considering the criteria for inclusion of the randomly selected institutions).

4) Closely related to the funding issue is the respondents' indication that the sources of teaching and learning of synonyms available to teachers is the traditional use of dictionaries and Thesaurus. This reiterates Murphy (2013)'s claim.

5) Another fund related issue is that, even in developed countries, software developers/institutions have copyright advantages. They licence to others who desire access at a favourable fee to the developers. Either as a developer or as a user, both sides of the coin have financial implications. The immaterial advantage to the developers is that, since educational technologies are most effective as context sensitive (as most 
software is) materials, the developers have the opportunity to maximise the outcome for self gain. This implies that if Nigeria would go this far in customizing her educational technology, there are numerous corresponding advantages for national development and growth as indigenous production would pick up. But if fund is not made available to address this constrain, at best Nigeria would be consuming what has been designed for other countries.

6) The National Policy on Education pronouncement favours lifelong learning "...to promote in service education". This may be harnessed to stimulate teachers' interest in Educational Technology because there appears to be a special shortage of manpower in this essential section.

7) The application of software to teaching and learning is time consuming but should cut across all level of formal education (primary, secondary and tertiary) and the non-formal education sector. Obstruction of academic calendar by incessant strike actions of academic staff; the unfavourable teachers versus learners ratio in the over-crowded institutions/classrooms and emphasize of Nigeria educational system on examination and certification leave little/no time to adopt and use educational technology tools and techniques.

\section{Recommendations/Conclusion}

1) Better funding for education and related fields is a cardinal requirement for general national development and educational technology development in particular. Lack of funding linadequate funding is a multi headed dragon which has ripple effects that cripple several aspects of human endeavour in ways that may not be directly visible. Different sectors interrelate in complex ways. Therefore, the down lines and up lines of Educational Technology should be adequately funded and monitored for implementation and most challenges would be fixed. The major institutional constraints (institutional readiness/provision for education technology services, training manpower and staff remunerations, developing relevant instructional material and creating conducive environment) are fund dependent.

2) Language is very dynamic. Therefore, considering the role of English Language in Nigeria, English language teachers in particular need to update skills with training on use of technology, computers and multimedia in the language classroom. This update can be made available in workshops and other related academic exercises.

3) The government and institutions should encourage lifelong learning in principles and practice by supporting autonomous learning and technology.

4) At the policy level, educational institutions should be programmed to adopt and diffuse Educational Technology as an education innovation through creating institutional readiness of educational technology. This is very essential because for educational technology to be effective in teaching and learning, the tools and other important aspects need to be customized to enhance context sensitivity. Many problems of implementing Educational Technology in Nigeria stem from adopting a first world concept in a third world context. The few facilities of educational technology available are lying idle over the ages in some Nigeria institutions. National investments to stimulate indigenous technology may be an opening for several puzzles that hinder Nigerian technological breakthrough.

5) Considering the functional roles of English Language in the country and the increasing need for blended learning models in English Language, Nigeria should make haste to integrate into the innovation and corresponding opportunities provided on the numerous platforms of CALL of which BNC is one.

6) On the whole, though educational technology may not be a panacea to all educational problems, a more careful and holistic planning, implementation and evaluation of the projects of educational technology should be carried out to enable Nigeria revisit and key into this world of seemingly endless adventures.

Government (through creative, systematic and comprehensive strategies) should liaise with relevant and related stakeholders (within and international) to facilitate a take up of Educational Technology in all Nigerians institutions and in no time, the positive multiple effects would manifest in a vibrant nation. This is a panacea for national development in Nigeria.

\section{References}

Adewoyi, J. A. (1991). Introduction to Educational Technology. Lagos: Johns-Lad Publishers.

Adina, H; Dedegikas, C and Walls, J. (2000). "EFL Academic Reading and Modern Technology: How can we turn our students into Independent Critical Readers?" TESL-EJ, Vol.4, No. 4.

British National Corpus (2000). The British National Corpus User Reference Guide: Retrieved from http:www.natcorp.ox.ac.uk. 
Cruse, D. A. (1986). Lexical Semantics. London: Cambridge University Press.

David, Mark (2004). BYU-BNC (based on the British National Corpus from Oxford University Press. Available online at: http:/corpus. byu.edu/bncl

Davies, J. Renuad (2011). " Second-language acquisition and the information age: How social software has created a new model of learning" TESL Canada Journal/ Revue TESL du Canada, Vol.28, No. 2. pp11-19.

Federal Republic of Nigeria (1981). "National Policy on Education". Lagos: Federal Government Press.

Imogie, A. I. (2002). Improving Teaching and Learning: An Introduction to Instructional Technology. Benin: Joe Seg Assoc.

Kelsen, Brent (2009). "Teaching EFL to the iGeneration: A survey of using Youtube as supplementary material with college EFL students in Taiwan" CALL-EJ Online, Vol.10, No.2.

McEnery, Tony; Xiao, Richard and Tono, Yukio (2006). Language Studies: An Advanced Resource Book. London: Routeledge.

Murphy, M. Lynne (2010). Lexical Meaning. London: Cambridge University Press.

Murphy, M. Lynne (2013). "What we talk about when we talk about synonyms and what it can tell us about Thesauruses". International Journal of Lexicography, Vol. 26, No. 3, pp 279-304.

Murphy, M. Lynne and Koskela, Anu (2010). Key Terms in Semantics. London: Continuum.

Norris, J. M and Ortega, L. (2006). Synthesizing Research on Language Teaching and Learning. Philadelphia, PA: John Benjamins.

Ogunranti, A. (1988). Problems and Prospects of Educational Technology in Nigeria. Ibadan: Heinemann.

Stubbs, Micheal (1996). Texts and Corpus Analysis: Computer-Assisted Studies of Language and Culture. Oxford: Black Well Publishers.

Stubbs, Micheal (2001). Words and Phrases: Corpus Studies of Lexical Semantics. Oxford: Black Well Publishers.

Warschaue, Mark (1996). "Comparing face-to-face and electronic discussion in second language classroom". CALICO Journal. Vol.13. No. 2, pp7-26.

Wray, Alison; Bloomer, Aileen (2006). Projects in Linguistics: A Practical Guide to Researching Language. London: Hodder Arnold.

Xiaoyin, H; Dedegikas, C and Walls, J (2011). "Using multimedia technology in teaching modern Greek language online in China: Development, implementation and evaluation". European Journal of Open, Distance and E-learning. 
